\title{
Novosphingobium soli sp. nov., isolated from soil
}

\author{
Correspondence \\ Peter Kämpfer \\ peter.kaempfer@umwelt. \\ uni-giessen.de \\ Chiu-Chung Young \\ ccyoung@mail.nchu.edu.tw
}

\author{
Peter Kämpfer, ${ }^{1}$ Chiu-Chung Young, ${ }^{2}$ Hans-Jürgen Busse, ${ }^{3}$ Shi-Yao Lin, ${ }^{2}$ \\ P. D. Rekha, ${ }^{4}$ A. B. Arun, ${ }^{4}$ Wen-Ming Chen, ${ }^{5}$ Fo-Ting Shen ${ }^{2}$ and Y.-H. $\mathrm{Wu}^{2}$ \\ ${ }^{1}$ Institut für Angewandte Mikrobiologie, Justus-Liebig-Universität Giessen, D-35392 Giessen, \\ Germany \\ ${ }^{2}$ Department of Soil and Environmental Sciences, College of Agriculture and Natural Resources, \\ National Chung Hsing University, Taichung, Taiwan, ROC \\ ${ }^{3}$ Institut für Bakteriologie, Mykologie und Hygiene, Veterinärmedizinische Universität, A-1210 Wien, \\ Austria \\ ${ }^{4}$ Yenepoya Research Center, Yenepoya University, University Rd, Deralakatee, Mangalore, \\ Karnataka State, India \\ ${ }^{5}$ Laboratory of Microbiology, Department of Seafood Science, National Kaohsiung Marine \\ University, Kaohsiung, Taiwan, ROC
}

A yellow-pigmented, Gram-negative, rod-shaped, non-spore-forming bacterium, strain CC-TPE $-1^{\top}$, was isolated from oil-contaminated soil near an oil refinery located in Kaohsiung County, Taiwan. 16S rRNA gene sequence analysis of strain CC-TPE-1 ${ }^{\top}$ showed highest sequence similarity to Novosphingobium naphthalenivorans TUT562 ${ }^{\top}$ (98.1\%), N. panipatense SM16 ${ }^{\top}(97.9 \%)$ and $N$. mathurense SM117 ${ }^{\top}(97.6 \%)$ and lower $(<97 \%)$ sequence similarity to all other Novosphingobium species. DNA-DNA hybridizations of strain CC-TPE-1 ${ }^{\top}$ with $N$. naphthalenivorans DSM $18518^{\top}, N$. panipatense SM16 ${ }^{\top}$ and $N$. mathurense SM117 ${ }^{\top}$ showed low relatedness of $30 \%$ (reciprocal $35 \%$ ), $29.1 \%$ (reciprocal $30.6 \%$ ) and $35 \%$ (reciprocal $23.6 \%$ ), respectively. The major respiratory quinone was ubiquinone $\mathrm{Q}-10$, the predominant fatty acid was $\mathrm{C}_{18: 1} \omega 7 \mathrm{c}(49.9 \%)$ and three 2-hydroxy fatty acids, $\mathrm{C}_{14: 0} 2-\mathrm{OH}(8.2 \%), \mathrm{C}_{15: 0}$ $2-\mathrm{OH}(2.45 \%)$ and $\mathrm{C}_{16: 0} 2-\mathrm{OH}(1.05 \%)$, were detected. Polar lipids consisted mainly of phosphatidylethanolamine, phosphatidylglycerol, phosphatidylcholine, phosphatidyldimethylethanolamine, two sphingoglycolipids, phosphatidylmonomethylethanolamine and several unidentified lipids, and a yellow pigment was also detected. The polyamine pattern contained the single major compound spermidine. Characterization by $16 \mathrm{~S}$ rRNA gene sequence analysis, physiological parameters, pigment analysis and polyamine, ubiquinone, polar lipid and fatty acid compositions revealed that strain $\mathrm{CC}-\mathrm{TPE}-1^{\top}$ represents a novel species of the genus Novosphingobium, for which we propose the name Novosphingobium soli sp. nov., with the type strain CC-TPE-1 ${ }^{\top}\left(=\mathrm{DSM} 22821^{\top}={\mathrm{CCM} 7706^{\top}}^{\top}\right.$ = CCUG 58493').
The genus Novosphingobium was proposed as a consequence of the dissection of the genus Sphingomonas (Yabuuchi et al., 1990), which was based on phylogenetic and chemotaxonomic analyses (Takeuchi et al., 2001). At the time of writing, 18 Novosphingobium species have been described with validly published names: the type species Novosphingobium capsulatum (Yabuuchi et al., 1990), N. rosa (Takeuchi et al., 1995), N. aromaticivorans, N. stygium and N. subterraneum (Balkwill et al., 1997), N. subarcticum (Takeuchi et al., 2001) (which has been reported to be a later

Abbreviations: pNA, $p$-nitroanilide; pNP, $p$-nitrophenyl.

The GenBank/EMBL/DDBJ accession number for the 16S rRNA gene sequence of strain CC-TPE- $1^{\top}$ is FJ425737. heterotypic synonym of $N$. resinovorum; Lim et al., 2007), $N$. hassiacum (Kämpfer et al., 2002), N. tardaugens (Fujii et al., 2003), N. pentaromativorans (Sohn et al., 2004), N. taihuense (Liu et al., 2005), N. lentum (Tiirola et al., 2005), N. nitrogenifigens (Addison et al., 2007), N. resinovorum (Lim et al., 2007), N. naphthalenivorans (Suzuki \& Hiraishi, 2007), N. acidiphilum (Glaeser et al., 2009), N. mathurense and $N$. panipatense (Gupta et al., 2009) and N. indicum (Yuan et al., 2009). Novosphingobium species have been isolated from a wide variety of habitats including soil, coastal and freshwater sediments (Balkwill et al., 1997; Sohn et al., 2004; Liu et al., 2005), activated sludge/wastewater treatment plants (Neef et al., 1999; Fujii et al., 2003) and a contaminated groundwater bioremediation reactor (Tiirola et al., 2002). 
Strain CC-TPE- $1^{\mathrm{T}}$ was isolated from oil-contaminated soil near an oil refinery located in Kaohsiung County, Taiwan. The strain showed single cells and formed small yellow colonies $(<0.5 \mathrm{~mm})$ with a smooth surface after $48 \mathrm{~h}$ at $25{ }^{\circ} \mathrm{C}$ on nutrient agar. Cell morphology was investigated by phase-contrast microscopy for cells grown on nutrient agar at $25{ }^{\circ} \mathrm{C}$. During exponential growth, rod-shaped cells of strain CC-TPE- $1^{\mathrm{T}}$ were $1.6 \pm 0.4 \mu \mathrm{m}$ long and $0.8 \pm 0.1 \mu \mathrm{m}$ wide and motile in the early exponential growth phase. Cells stained Gram-negative and were positive for cytochrome oxidase in a delayed reaction as determined by using an oxidase test (Merck). Endospores could not be detected.

For 16S rRNA gene sequencing, chromosomal DNA was extracted as described by Pitcher et al. (1989) and a $1461 \mathrm{bp}$ fragment of the 16S rRNA gene was amplified using primers targeting conserved regions of the 16S rRNA gene, $8 \mathrm{~F}$ (positions 8-27, Escherichia coli numbering; Brosius et al., 1981) and 1492R (1492-1510; Lane, 1991). Sequencing of the DNA fragment was done with primers $8 \mathrm{~F}$ and $1492 \mathrm{R}$ and two additional reverse primers, 907R (907-926) and 1100R (1100-1115) (Lane, 1991), using the Big Dye terminator cycle sequencing reaction kit and an ABI Prism 310 Genetic Analyzer (Applied Biosystems). DNA sequences were processed in the software package MEGA (Kumar et al., 2004) and phylogenetic analysis was performed with the ARB software package (Ludwig et al., 2004). Similarities were calculated on the basis of a pairwise comparison (ARB software) and phylogenetic trees were obtained by the neighbour-joining and maximumlikelihood methods including bootstrap values based on 1000 replicates. Comparison of the 16S rRNA gene sequence of strain CC-TPE- $1^{\mathrm{T}}$ revealed highest similarity to N. naphthalenivorans TUT $562^{\mathrm{T}}$ (98.1\%), N. panipatense $\mathrm{SM}^{\mathrm{T}}{ }^{\mathrm{T}}(97.9 \%)$ and N. mathurense SM117 ${ }^{\mathrm{T}}(97.6 \%)$ and lower $(<97 \%)$ sequence similarity to representatives of all other Novosphingobium species (Fig. 1). DNA-DNA hybridization experiments with strain CC-TPE- $1^{\mathrm{T}}$ and the type strains of the three species given above were done as described previously (Kämpfer et al., 2002) and revealed low relatedness values of $30 \%$ (reciprocal $35 \%$ ) to $N$. naphthalenivorans DSM $18518^{\mathrm{T}}, 29.1 \%$ (reciprocal $30.6 \%$ ) to N. panipatense $\mathrm{SM}_{1} 6^{\mathrm{T}}$ and $35 \%$ (reciprocal $23.6 \%$ ) to N. mathurense $\mathrm{SM} 117^{\mathrm{T}}$.

Further characterization of strain CC-TPE- ${ }^{\mathrm{T}}$ was performed using a substrate assimilation panel and enzyme tests with chromogenic substrates [p-nitrophenyl (pNP) and $p$-nitroanilide (pNA)-linked substrates] (Kämpfer et al., 1991). Results of comparative characterizations are given in Table 1 . The results showed that strain CC-TPE- $1^{\mathrm{T}}$ can be clearly distinguished from the most closely related Novosphingobium species.

Fatty acids were analysed from biomass grown on tryptone soy agar as described by Kämpfer \& Kroppenstedt (1996). The detailed fatty acid profile of strain CC-TPE- $1^{\mathrm{T}}$ is shown in Table 2 . The dominant fatty acid of CC-TPE- $1^{\mathrm{T}}$

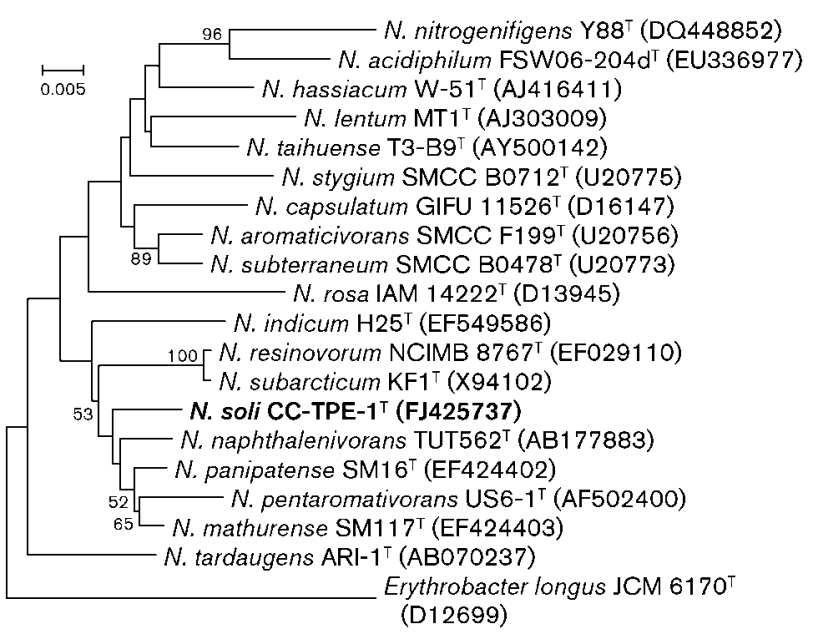

Fig. 1. Phylogenetic tree calculated using the neighbour-joining method indicating the phylogenetic relationship of strain CC-TPE$1^{\top}$ to members of other Novosphingobium species. The sequence of Erythrobacter longus JCM $6170^{\top}$ was used as an outgroup. Numbers at nodes indicate percentages of bootstrap support based on 1000 resampled datasets. Bar, 5 substitutions per 1000 nucleotide positions.

was $\mathrm{C}_{18: 1} \omega 7 c(49.9 \%)$; three 2-hydroxy fatty acids, $\mathrm{C}_{14: 0}$ $2-\mathrm{OH}(8.2 \%), \mathrm{C}_{15: 0} \quad 2-\mathrm{OH}(2.45 \%)$ and $\mathrm{C}_{16: 0} \quad 2-\mathrm{OH}$ $(1.05 \%)$, could be detected in small amounts, but no 3hydroxy fatty acids were detected (Table 2). Takeuchi et al. (2001) distinguished the genus Novosphingobium from the genera Sphingomonas sensu stricto, Sphingopyxis and Sphingobium by the absence of major 2-hydroxy fatty acids other than $\mathrm{C}_{14: 0}$ 2-OH. However, strain CC-TPE-1 ${ }^{\mathrm{T}}$ contained rather similar amounts of $\mathrm{C}_{14: 0} 2-\mathrm{OH}, \mathrm{C}_{15: 0}$ 2-OH and $\mathrm{C}_{16: 0} 2-\mathrm{OH}$ fatty acids, which was also reported for $N$. hassiacum $\mathrm{W}-51^{\mathrm{T}}$ and N. acidiphilum FSW06-204d (Kämpfer et al., 2002; Glaeser et al., 2009).

For polyamine, quinone and polar lipid analyses, cells were grown on PYE agar $(0.3 \%$ peptone from casein, $0.3 \%$ yeast extract, $\mathrm{pH} 7.2$, supplemented with $3 \%$ salts used for seawater aquaria). Quinones and polar lipids were extracted and analysed by the methods described by Tindall (1990a, b) and Altenburger et al. (1996) and polyamines as described by Busse \& Auling (1988). For HPLC analyses of the quinones and polyamines, the apparatus described by Stolz et al. (2007) was used. The quinone system consisted of ubiquinones Q-10 (79\%) and Q-9 (21\%). The polyamine pattern contained the major compound spermidine $[25.5 \mu \mathrm{g}$ (g dry weight $\left.)^{-1}\right]$ and trace amounts of spermine $[<0.1 \mu \mathrm{g}$ (g dry weight $\left.)^{-1}\right]$. The polar lipid profile (Fig. 2) consisted of the major lipids phosphatidylethanolamine, phosphatidylglycerol, phosphatidylcholine, phosphatidyldimethylethanolamine, phosphatidylmonomethylethanolamine and two sphingoglycolipids and minor amounts of an unidentified glycolipid, two aminolipids and two lipids not stained by any of the specific spray reagents used. Surprisingly, 
Table 1. Differentiation of strain CC-TPE- $1^{\top}$ and type strains of closely related Novosphingobium species

Strains: 1 , CC-TPE-1 $1^{\mathrm{T}} ; 2, N$. naphthalenivorans DSM $18518^{\mathrm{T}} ; 3, N$. panipatense $\mathrm{SM} 16^{\mathrm{T}} ; 4, N$. mathurense $\mathrm{SM} 117^{\mathrm{T}}$; 5 , N. capsulatum ATCC $14666^{\mathrm{T}}$ [data from Tiirola et al. (2005), obtained with the same method]. -, Negative; +, positive; (+), weakly positive. Data were obtained in this study, unless indicated otherwise. All strains were positive for hydrolysis of L-alanine pNA and 2-deoxythymidine-5'pNP phosphate and for assimilation of D-glucose $\mathrm{e}^{*} \dagger$ and L-proline $\dagger$; all strains were negative for hydrolysis of $\mathrm{pNP} \beta$-D-galactopyranoside and $\mathrm{pNP} \beta$-D-xylopyranoside and for assimilation of L-sorbose, Dmannitol ${ }^{*} \dagger$ and citrate ${ }^{*}$.

\begin{tabular}{|lccccc|}
\hline Characteristic & $\mathbf{1}$ & $\mathbf{2}$ & $\mathbf{3}$ & $\mathbf{4}$ & $\mathbf{5}$ \\
\hline Hydrolysis of: & & & & & \\
Aesculin & - & $(+)^{*}$ & $-\dagger$ & $+\dagger$ & + \\
pNP $\alpha$-D-glucopyranoside & - & + & + & + & + \\
bis-pNP phosphate & + & - & + & + & + \\
pNP phenylphosphonate & + & - & + & + & + \\
pNP $\alpha$-D-glucuronide & + & - & - & + & + \\
Assimilation of: & & & & & \\
L-Arabinose & + & $+^{*}$ & $(+) \dagger$ & $+\dagger$ & $(+)$ \\
D-Fructose & $(+)$ & - & $(+) \dagger$ & $+\dagger$ & - \\
D-Galactose & - & - & $(+) \dagger$ & $+\dagger$ & + \\
Maltose & - & $+^{*}$ & $(+) \dagger$ & $+\dagger$ & + \\
L-Rhamnose & - & - & $-\dagger$ & $+\dagger$ & + \\
Sucrose & - & - & $(+) \dagger$ & $+\dagger$ & + \\
Acetate & + & - & - & + & - \\
L-Malate & + & - & - & - & + \\
Pyruvate & + & + & + & + & - \\
L-Histidine & - & - & $(+) \dagger$ & $+\dagger$ & + \\
L-Leucine & + & - & + & - & + \\
\hline
\end{tabular}

${ }^{*}$ Result in accordance with that published for N. naphthalenivorans DSM $18518^{\mathrm{T}}$ by Suzuki \& Hiraishi (2007).

$\dagger$ Result in accordance with those published for N. panipatense SM16 ${ }^{\mathrm{T}}$ and N. mathurense SM117 ${ }^{\mathrm{T}}$ by Gupta et al. (2009).

diphosphatidylglycerol, usually found in representatives of the Sphingomonadaceae, could not be detected. Unfortunately, $N$. naphthalenivorans was not analysed for this trait and, hence, it is not known whether the absence of diphosphatidylglycerol from the lipid profile of CC-TPE- $1^{\mathrm{T}}$ is useful for differentiation from its close relatives. A yellow pigment spot that gave a positive reaction with $\alpha$-naphthol was also detected, indicating the presence of a sugar moiety in the pigment. However, strain CC-TPE- $1^{\mathrm{T}}$ shares the chemotaxonomic traits listed in the genus description (Takeuchi et al., 2001), including a polyamine pattern with the major compound spermidine (sym-homospermidine absent), ubiquinone Q-10 and a polar lipid profile showing sphingoglycolipids. A combination of the observed chemotaxonomic and physiological differences (absence of diphosphatidylglycerol, production of three hydroxylated fatty acids and several physiological features) warrant the proposal of a separate species to accommodate strain CCTPE- $1^{\mathrm{T}}$.
Table 2. Whole-cell fatty acid profiles of strain CC-TPE-1 ${ }^{\top}$ and type strains of closely related Novosphingobium species

Strains: 1, CC-TPE-1 ${ }^{\mathrm{T}} ; 2, N$. naphthalenivorans DSM $18518^{\mathrm{T}} ; 3, N$. panipatense $\mathrm{SM} 16^{\mathrm{T}} ; 4$, N. mathurense $\mathrm{SM} 117^{\mathrm{T}} ; 5$, N. capsulatum ATCC $14666^{\mathrm{T}}$ [data from Kämpfer et al. (2002), obtained with the same method]. Data are from this study, unless indicated. Values represent percentages of total fatty acids; - , not detected. Double bonds are located by counting from the methyl $(\omega)$ end of the carbon chain.

\begin{tabular}{|lccccc|}
\hline Fatty acid & $\mathbf{1}$ & $\mathbf{2}$ & $\mathbf{3}$ & $\mathbf{4}$ & $\mathbf{5}$ \\
\hline Saturated fatty acids & & & & & \\
$\mathrm{C}_{14: 0}$ & - & - & - & 0.5 & - \\
$\mathrm{C}_{15: 0}$ & 0.6 & 0.9 & - & 0.5 & - \\
$\mathrm{C}_{16: 0}$ & 7.3 & 6.0 & 6.5 & 5.4 & 8.1 \\
$\mathrm{C}_{17: 0}$ & - & 0.9 & - & - & - \\
$\mathrm{C}_{18: 0}$ & 0.8 & - & - & - & - \\
Unsaturated fatty acids & & & & & \\
$\mathrm{C}_{16: 1} \omega 5 c$ & 1.9 & 1.4 & 3.4 & 2.8 & 1.7 \\
$\mathrm{C}_{17: 1} \omega 8 c$ & 1.7 & 1.6 & - & - & - \\
$\mathrm{C}_{17: 1} \omega 6 c$ & 11.0 & 15.2 & 2.4 & 5.2 & - \\
$\mathrm{C}_{18: 1} \omega 7 c$ & 49.9 & 52.0 & 57.9 & 61.2 & 64.8 \\
$\mathrm{C}_{18: 1} \omega 5 c$ & 0.8 & 0.8 & - & 1.4 & - \\
$11-\mathrm{Methyl} \mathrm{C}_{18: 1} \omega 7 c$ & 7.6 & - & 0.6 & 1.2 & - \\
Hydroxy fatty acids $_{\text {Hydr }}$ & & & & & \\
$\mathrm{C}_{13: 0} 2-\mathrm{OH}$ & 0.7 & 0.4 & & - & - \\
$\mathrm{C}_{14: 0} 2-\mathrm{OH}$ & 8.2 & 7.1 & 7.7 & 6.2 & 14.7 \\
$\mathrm{C}_{15: 0} 2-\mathrm{OH}$ & 2.4 & 3.2 & - & 0.4 & - \\
$\mathrm{C}_{16: 0} 2-\mathrm{OH}$ & 1.0 & 1.4 & 1.4 & 4.1 & - \\
iso- $\mathrm{C}_{16: 0} 3-\mathrm{OH}$ & - & - & - & 1.3 & - \\
Summed feature 3* & 6.3 & 9.0 & 19.4 & 25.7 & 6.7 \\
& & & & & \\
\hline
\end{tabular}

*Summed features represent groups of two or three fatty acids that could not be separated by GLC in the MIDI System. Summed feature 3 contains $\mathrm{C}_{16: 1} \omega 7 c$ and/or iso- $\mathrm{C}_{15: 0} 2-\mathrm{OH}$.

\section{Description of Novosphingobium soli sp. nov.}

Novosphingobium soli (so'li. L. neut. gen. n. soli of soil, the source of the type strain).

The species shares all the characteristics of the genus as given by Takeuchi et al. (2001). Cells are rod-shaped, $1.6 \pm 0.4 \mu \mathrm{m}$ long and $0.8 \pm 0.1 \mu \mathrm{m}$ wide in the midexponential phase, and motile in the early exponential phase. Growth is observed on peptone/yeast extract (PYE) agar and nutrient, tryptone soy and R2A agars. On nutrient agar, circular yellow colonies are formed after incubation for 2-3 days at $25{ }^{\circ} \mathrm{C}$. Cells stain Gram-negative and are positive for cytochrome oxidase and catalase-negative. Endospores are not observed. On nutrient agar, growth occurs at $4-32{ }^{\circ} \mathrm{C}$, but not at 37 or $42{ }^{\circ} \mathrm{C}$, and at $\mathrm{pH} 4.5-7.0$, but not at $\mathrm{pH} 3.5$ or 8.5. Hydrolyses L-alanine pNA, Lglutamate- $\gamma$-carboxy pNA and L-proline pNA and is positive for the assimilation of L-arabinose, D-fructose (weak), Dglucose, trehalose, D-xylose, acetate, DL-3-hydroxybutyrate, pyruvate, L-leucine and L-proline. Negative for assimilation of cellobiose, D-galactose, maltose, D-mannose, L-rhamnose, 


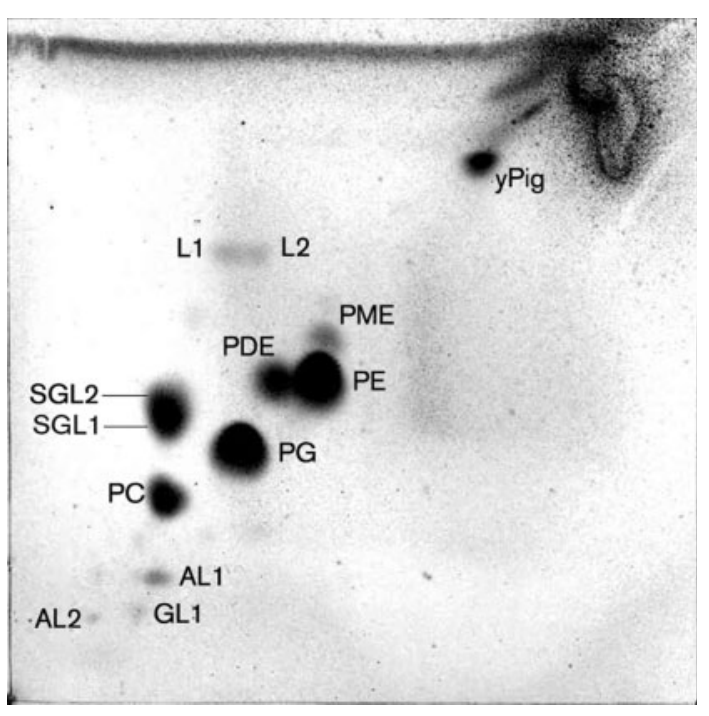

Fig. 2. Total polar lipid profile of strain CC-TPE-1 ${ }^{\top}$ after twodimensional TLC and detection with molybdatophosphoric acid. PC, Phosphatidylglycerol; PDE, phosphatidyldimethylethanolamine; $P E$, phosphatidylethanolamine; PG, phosphatidylglycerol; PME, phosphatidylmonomethylethanolamine; SGL1, 2, sphingoglycolipids; GL1, unidentified glycolipid; AL1, 2, unknown aminolipids; L1, 2, unknown polar lipids; yPig, yellow pigment staining positively with $\alpha$-naphthol.

sucrose, L-malate, 2-oxoglutarate, L-sorbose, D-mannitol, citrate, DL-lactate, DL-3-aminobutyrate, benzoate, 4-hydroxybenzoate, L-histidine and L-phenylalanine. Polar lipid profile consists of the predominant lipids phosphatidylethanolamine, phosphatidylglycerol, phosphatidylcholine, phosphatidyldimethylethanolamine, phosphatidylmonomethylethanolamine and two sphingoglycolipids and minor amounts of an unidentified glycolipid, two aminolipids and two polar lipids not stained by any of the specific spray reagents used; diphosphatidylglycerol is absent. The polyamine pattern contains the major amine spermidine and the quinone system contains ubiquinone Q-10 with moderate amounts of Q-9. The fatty acid profile consists of the major component $\mathrm{C}_{18: 1} \omega 7 c$; three 2-hydroxy fatty acids, $\mathrm{C}_{14: 0} 2$ $\mathrm{OH}, \mathrm{C}_{15: 0} 2-\mathrm{OH}$ and $\mathrm{C}_{16: 0} 2-\mathrm{OH}$, are also found in small amounts, but no 3-hydroxy fatty acids are detected.

The type strain, CC-TPE $-1^{\mathrm{T}}\left(=\mathrm{DSM} 22821^{\mathrm{T}}=\mathrm{CCM} 7706^{\mathrm{T}}\right.$ $=$ CCUG $58493^{\mathrm{T}}$ ), was isolated from oil-contaminated soil near an oil refinery located in Kaohsiung County, Taiwan.

\section{Acknowledgements}

We thank Professor Rup Lal for providing the type strains of $N$. panipatense and N. mathurense and Gundula Will, Maria Sowinsky and W.-H. Huang for technical assistance.

\section{References}

Addison, S. L., Foote, S. M., Reid, N. M. \& Lloyd-Jones, G. (2007). Novosphingobium nitrogenifigens sp. nov., a polyhydroxyalkanoate- accumulating diazotroph isolated from a New Zealand pulp and paper wastewater. Int J Syst Evol Microbiol 57, 2467-2471.

Altenburger, P., Kämpfer, P., Makristathis, A., Lubitz, W. \& Busse, H.-J. (1996). Classification of bacteria isolated from a medieval wall painting. J Biotechnol 47, 39-52.

Balkwill, D. L., Drake, G. R., Reeves, R. H., Frederickson, J. K., White, D. C., Ringelberg, D. B., Chandler, D. P., Romine, M. F., Kennedy, D. W. \& Spadoni, C. M. (1997). Taxonomic study of aromaticdegrading bacteria from deep-terrestrial-subsurface sediments and description of Sphingomonas aromaticivorans sp. nov., Sphingomonas subterranea sp. nov., and Sphingomonas stygia sp. nov. Int J Syst Bacteriol 47, 191-201.

Brosius, J., Dull, T., Sleeter, D. \& Noller, H. (1981). Gene organization and primary structure of a ribosomal RNA operon from Escherichia coli. J Mol Biol 148, 107-127.

Busse, H.-J. \& Auling, G. (1988). Polyamine pattern as a chemotaxonomic marker within the Proteobacteria. Syst Appl Microbiol 11, $1-8$.

Busse, H.-J., Kämpfer, P. \& Denner, E. B. M. (1999). Chemotaxonomic characterization of Sphingomonas. J Ind Microbiol Biotechnol 23, 242-251.

Busse, H.-J., Denner, E. B. M., Buczolits, S., Salkinoja-Salonen, M., Bennasar, A. \& Kämpfer, P. (2003). Sphingomonas aurantiaca sp. nov., Sphingomonas aerolata sp. nov. and Sphingomonas faeni sp. nov., air- and dustborne and Antarctic, orange-pigmented, psychrotolerant bacteria, and emended description of the genus Sphingomonas. Int $J$ Syst Evol Microbiol 53, 1253-1260.

Fujii, K., Kikuchi, S., Satomi, M., Ushio-Sata, N. \& Morita, N. (2003). Novosphingobium tardaugens sp. nov., an oestradiol-degrading bacterium isolated from activated sludge of a sewage treatment plant in Tokyo. Int J Syst Evol Microbiol 53, 47-52.

Glaeser, S. P., Kämpfer, P., Busse, H.-J., Langer, S. \& Glaeser, J. (2009). Novosphingobium acidiphilum sp. nov., an acidophilic saltsensitive bacterium isolated from the humic acid-rich Lake Grosse Fuchskuhle. Int J Syst Evol Microbiol 59, 323-330.

Gupta, S. K., Lal, D. \& Lal, R. (2009). Novosphingobium panipatense sp. nov. and Novosphingobium mathurense sp. nov., from oil-contaminated soil. Int J Syst Evol Microbiol 59, 156-161.

Kämpfer, P. \& Kroppenstedt, R. M. (1996). Numerical analysis of fatty acid patterns of coryneform bacteria and related taxa. Can $J$ Microbiol 42, 989-1005.

Kämpfer, P., Steiof, M. \& Dott, W. (1991). Microbiological characterization of a fuel-oil contaminated site including numerical identification of heterotrophic water and soil bacteria. Microb Ecol 21, 227-251.

Kämpfer, P., Witzenberger, R., Denner, E. B. M., Busse, H.-J. \& Neef, A. (2002). Novosphingobium hassiacum sp. nov., a new species isolated from an aerated sewage pond. Syst Appl Microbiol 25, 37-45.

Kim, M. K., Schubert, K., Im, W.-T., Kim, K.-H., Lee, S.-T. \& Overmann, J. (2007). Sphingomonas kaistensis sp. nov., a novel alphaproteobacterium containing pufLM genes. Int $J$ Syst Evol Microbiol 57, 1527-1534.

Kumar, S., Tamura, K. \& Nei, M. (2004). MEGA3: integrated software for molecular evolutionary genetics analysis and sequence alignment. Brief Bioinform 5, 150-163.

Lane, D. J. (1991). 16S/23S rRNA sequencing. In Nucleic Acid Techniques in Bacterial Systematics, pp. 115-175. Edited by E. Stackebrandt \& M. Goodfellow. Chichester: Wiley.

Lim, Y. W., Moon, E. Y. \& Chun, J. (2007). Reclassification of Flavobacterium resinovorum Delaporte and Daste 1956 as Novosphingobium resinovorum comb. nov., with Novosphingobium 
subarcticum (Nohynek et al. 1996) Takeuchi et al. 2001 as a later heterotypic synonym. Int J Syst Evol Microbiol 57, 1906-1908.

Liu, Z.-P., Wang, B.-J., Liu, Y.-H. \& Liu, S.-J. (2005). Novosphingobium taihuense sp. nov., a novel aromatic-compound-degrading bacterium isolated from Taihu Lake, China. Int J Syst Evol Microbiol 55, 1229-1232.

Ludwig, W., Strunk, O., Westram, R., Richter, L., Meier, H., Yadhukumar, Buchner, A., Lai, T., Steppi, S. \& other authors (2004). ARB: a software environment for sequence data. Nucleic Acids Res 32, 1363-1371.

Neef, A., Witzenberger, R. \& Kämpfer, P. (1999). Detection of sphingomonads and in situ identification in activated sludge using $16 \mathrm{~S}$ rRNA-targeted oligonucleotide probes. J Ind Microbiol Biotechnol 23, 261-267.

Pitcher, D. G., Saunders, N. A. \& Owen, R. J. (1989). Rapid extraction of bacterial genomic DNA with guanidium thiocyanate. Lett Appl Microbiol 8, 151-156.

Sohn, J. H., Kwon, K.-K., Kang, J.-H., Jung, H.-B. \& Kim, S.-J. (2004). Novosphingobium pentaromativorans sp. nov., a high-molecular-mass polycyclic aromatic hydrocarbon-degrading bacterium isolated from estuarine sediment. Int J Syst Evol Microbiol 54, 1483-1487.

Stolz, A., Busse, H.-J. \& Kämpfer, P. (2007). Pseudomonas knackmussii sp. nov. Int J Syst Evol Microbiol 57, 572-576.

Suzuki, S. \& Hiraishi, A. (2007). Novosphingobium naphthalenivorans sp. nov., a naphthalene-degrading bacterium isolated from polychlorinated-dioxin-contaminated environments. J Gen Appl Microbiol 53, 221-228.

Takeuchi, M., Sakane, T., Miyoko, Y., Kazuhide, Y., Hamana, K. \& Yokota, A. (1995). Taxonomic study of bacteria isolated from plants: proposal of Sphingomonas rosa sp. nov., Sphingomonas pruni sp. nov.,
Sphingomonas asaccharolytica sp. nov., and Sphingomonas mali sp. nov. Int J Syst Bacteriol 45, 334-341.

Takeuchi, M., Hamana, K. \& Hiraishi, A. (2001). Proposal of the genus Sphingomonas sensu stricto and three new genera, Sphingobium, Novosphingobium and Sphingopyxis, on the basis of phylogenetic and chemotaxonomic analyses. Int J Syst Evol Microbiol 51, 1405-1417.

Tiirola, M. A., Männistö, M. K., Puhakka, J. A. \& Kulomaa, M. S. (2002). Isolation and characterization of Novosphingobium sp. strain MT1, a dominant polychlorophenol-degrading strain in a groundwater bioremediation system. Appl Environ Microbiol 68, 173-180.

Tiirola, M. A., Busse, H.-J., Kämpfer, P. \& Männistö, M. K. (2005). Novosphingobium lentum sp. nov., a psychrotolerant bacterium from a polychlorophenol bioremediation process. Int J Syst Evol Microbiol 55, 583-588.

Tindall, B. J. (1990a). A comparative study of the lipid composition of Halobacterium saccharovorum from various sources. Syst Appl Microbiol 13, 128-130.

Tindall, B. J. (1990b). Lipid composition of Halobacterium lacusprofundi. FEMS Microbiol Lett 66, 199-202.

Yabuuchi, E., Yano, I., Oyaizu, H., Hashimoto, Y., Ezaki, T. \& Yamamoto, H. (1990). Proposals of Sphingomonas paucimobilis gen. nov. and comb. nov., Sphingomonas parapaucimobilis sp. nov., Sphingomonas yanoikuyae sp. nov., Sphingomonas adhaesiva sp. nov., Sphingomonas capsulata comb. nov., and two genospecies of the genus Sphingomonas. Microbiol Immunol 34, 99-119.

Yuan, J., Lai, Q., Zheng, T. \& Shao, Z. (2009). Novosphingobium indicum sp. nov., a polycyclic aromatic hydrocarbon-degrading bacterium isolated from a deep-sea environment. Int J Syst Evol Microbiol 59, 2084-2088. 